\title{
A COMPARATIVE EVALUATION OF LIVER LOBE SIZE/ALBUMIN RATIO AND PLATELET COUNT/SPLEEN DIAMETER RATIO AS NON-INVASIVE PREDICTORS OF OESOPHAGEAL VARICES IN PATIENTS WITH LIVER CIRRHOSIS
}

\author{
${ }^{1}$ Associate Professor, Department of Medicine, Government Medical College, Amritsar. \\ 2Junior Resident, Department of Medicine, Government Medical College, Amritsar. \\ ${ }^{3}$ Assistant Professor, Department of Medicine, Government Medical College, Amritsar. \\ $4 J u n i o r$ Resident, Department of Medicine, Government Medical College, Amritsar. \\ 5Junior Resident, Department of Medicine, Government Medical College, Amritsar. \\ 6Junior Resident, Department of Medicine, Government Medical College, Amritsar. \\ 7 Junior Resident, Department of Medicine, Government Medical College, Amritsar. \\ 8Junior Resident, Department of Medicine, Government Medical College, Amritsar.
}

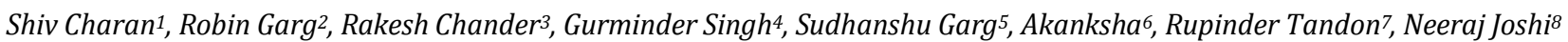

ABSTRACT

\section{BACKGROUND}

Oesophageal varices (EV) development is among the major complications of liver cirrhosis. Therefore, the current guidelines recommend screening of all liver cirrhosis patients for EV by endoscopy, but repeated endoscopic examinations are unpleasant for the patients, are not cost-effective and pose additional burden to endoscopic units. Therefore, non-invasive predictors of EV have been studied.

The aim is to comparatively evaluate platelet count/spleen diameter (PC/SD) ratio, right liver lobe diameter (RLLD)/albumin ratio \& left liver lobe diameter (LLLD)/albumin ratio as the non-invasive predictors of EV \& their grading in patients with liver cirrhosis.

\section{MATERIALS AND METHODS}

This study included 100 patients of liver cirrhosis which were subjected to laboratory investigations including platelet count \& serum albumin concentration, abdominal ultrasound including measurement of RLLD, LLLD \& spleen diameter and upper gastrointestinal endoscopy. PC/SD ratio, RLLD/albumin ratio \& LLLD/albumin ratio were then calculated \& comparatively evaluated statistically for their correlation with the presence \& grading of EV.

\section{RESULTS}

$\mathrm{PC} / \mathrm{SD}$ ratio, RLLD/albumin ratio and LLLD/albumin ratio had highly significant correlations with the presence and grading of EV ( $p<0.001$ for each). The sensitivity, specificity and accuracy of PC/SD ratio in prediction of EV was $90.2 \%, 88.9 \%$ and $90 \%$ respectively at the best cut-off value of 1167.25 as calculated by applying receiver operating characteristic (ROC) curve. [AUC (Area under curve) $=0.965$ ]. The sensitivity, specificity and accuracy of RLLD/albumin ratio in prediction of EV was 74.4\%, 94.4\% and $78 \%$ respectively at the best cut-off value of 4.272 (AUC=0.835). The sensitivity, specificity and accuracy of LLLD/albumin ratio in prediction of $\mathrm{EV}$ was $89 \%, 83.3 \%$ and $88 \%$ respectively at the best cut-off value of 1.939 (AUC=0.931). PC/SD ratio, having the highest sensitivity, accuracy \& area under ROC curve, was the best predictor of EV, followed by the LLLD/albumin ratio, which was further followed by RLLD/albumin ratio.

\section{CONCLUSION}

$\mathrm{PC} / \mathrm{SD}$ ratio, RLLD/albumin ratio \& LLLD/albumin ratio are cost-effective noninvasive parameters that can provide accurate information pertinent to predict the presence \& grading of EV in liver cirrhosis patients \& amongst them PC/SD ratio is the b est predictor of EV, followed by LLLD/albumin ratio, which is further followed by RLLD/albumin ratio.

\section{KEYWORDS}

Left Liver Lobe Diameter/Albumin Ratio, Platelet Count, Right Liver Lobe Diameter/Albumin Ratio, Spleen Diameter, Upper Gastrointestinal Endoscopy.

HOW TO CITE THIS ARTICLE: Charan S, Garg R, Chander R, et al. A comparative evaluation of liver lobe size/albumin ratio and platelet count/spleen diameter ratio as non-invasive predictors of oesophageal varices in patients with liver cirrhosis. J. Evolution Med. Dent. Sci. 2017;6(23):1858-1866, DOI: 10.14260/Jemds/2017/409

Financial or Other, Competing Interest: None.

Submission 27-02-2017, Peer Review 11-03-2017,

Acceptance 13-03-2017, Published 20-03-2017.

Corresponding Author:

Robin Garg,

Luxmi Fertilizers, Shop No. 76,

Grain Market, Rampura Phul,

Dist. Bathinda-151103.

E-mail: robingarg1989@yahoo.com

DOI: $10.14260 /$ jemds/2017/409

\section{BACKGROUND}

The incidence of Oesophageal varices (EV) in liver cirrhosis patients is approximately $60-80 \%$.(1) The risk of bleeding from varices is $25 \%-35 \%$ with majority of the initial bleeding occurring within first year of varices detection.(2) The mortality from each episode of variceal bleeding is $17 \%$ 57\%.(3),(4) Therefore, the current guidelines recommend screening of all liver cirrhosis patients by repeated upper gastrointestinal endoscopy to identify those at risk of bleeding so that they can be administered prophylactic therapy timely with endoscopic variceal band ligation and 
nonselective beta blockers which can decrease the risk of Oesophageal bleeding by $50 \% .(5),(6),(7)$ But this screening is invasive and is not cost-effective. It would result in a large number of unnecessary endoscopies and additional burden to endoscopic units especially in developing countries where the capacity is limited to satisfy this growing demand of endoscopy.(8) Also repeated endoscopic examinations are unpleasant for the patients. Thus, the need for a simple, cheap and noninvasive method that can predict $\mathrm{EV}$ is of outmost importance to avoid endoscopy in patients with a low risk of varices. Therefore, various non-invasive parameters have been studied to predict EV in cirrhotic patients including platelet count/spleen diameter (PC/SD) ratio, right liver lobe diameter (RLLD)/albumin ratio and left liver lobe diameter (LLLD)/albumin ratio. These parameters are also costeffective because these are based on ultrasonographic measurements and laboratory tests which are routinely performed in cirrhotic patients.

In 2003, Giannini et al,(9) first of all, introduced the use of the $\mathrm{PC} / \mathrm{SD}$ ratio as a tool to predict $\mathrm{EV}$ to link thrombocytopenia to splenomegaly to introduce a variable that takes into consideration that thrombocytopenia is mainly due to hypersplenism secondary to portal hypertension though there are many other factors also for thrombocytopenia in cirrhosis other than portal hypertension including shortened mean platelet lifetime, decreased thrombopoietin (TPO) production or the myelotoxic effects of hepatitis C virus.(10) Since then numerous studies have been done which concluded that the PC/SD ratio can be used as a predictor of EV. Combining RLLD as ultrasonographic parameter and serum albumin concentration as laboratory parameter of liver function, Alempijevic $\mathrm{T}$ et al(11),(12) in 2007, concluded for the first time in history that the RLLD/albumin ratio can be used as a noninvasive predictor of $\mathrm{EV}$ and since then many other studies have been done which have also concluded the same. In 2014, Laeeq S Mudassir et al(13) performed a study for the predictability of LLLD/albumin ratio \& concluded that the LLLD/albumin ratio can be used as a non-invasive predictor of EV. They introduced the use of LLLD/albumin ratio by taking into account the compensatory hypertrophy of left lobe of liver during early stages of cirrhosis. As the disease progresses to the late stage, the total liver volume has atrophied all the more and that change certainly affects the left lobe such that it is unable to maintain the need for compensation; therefore, the actual volume could not be significantly larger, but the left lateral lobe is relatively larger. Hence, the LLLD/albumin ratio keeps on working in late stages of cirrhosis. Therefore, in late stages of cirrhosis, the RLLD/albumin ratio becomes less reliable as both right liver lobe diameter and albumin decline, while the LLLD/albumin ratio still retains its validity.(13)

Laeeq S Mudassir et al(13) have also done comparison between the diagnostic performance of RLLD/albumin ratio and LLLD/albumin ratio and have concluded that LLLD/albumin ratio is a better predictor of $\mathrm{EV}$ than RLLD/albumin ratio. There are few comparative studies between PC/SD ratio and RLLD/albumin ratio, e.g. study by Mostafa HM et al(14) in 2013, which has concluded that PC/SD ratio has higher sensitivity than RLLD/albumin ratio to predict EV. But there is no study available till now in the literature for the comparison of all the three ratios i.e. PC/SD ratio, RLLD/albumin ratio and LLLD/albumin ratio as which one of these is best predictor of EV. Therefore, the present study has been conducted to compare all the three ratios i.e. PC/SD ratio, RLLD/albumin ratio and LLLD/albumin ratio as noninvasive predictors of $\mathrm{EV}$.

\section{MATERIALS AND METHODS}

The present study included 100 patients of either sex of age 18 years \& above, diagnosed to be a case of liver cirrhosis attending OPD/admitted in various wards of Guru Nanak Dev Hospital and allied group of hospitals attached to Government Medical College, Amritsar. The study was conducted from March 2015 to September 2016. It was conducted after approval from institutional thesis and ethical committee. The diagnosis of cirrhosis was based on a combination of clinical features, laboratory tests $\&$ abdominal ultrasound evaluation.

We excluded from the study patients with previous variceal bleeding, who previously had undergone injection sclerotherapy, band ligation or surgery for Oesophageal varices (TIPS etc.), who were taking beta blockers or other vasoactive agents, patients with hepatocellular carcinoma, primary haematological disorders, portal vein thrombosis, HIV infection, renal disease, pulmonary disease, severe or unstable cardiovascular disease, patients in whom endoscopy was contraindicated \& patients with coexistent illness or infection that could influence the liver \& spleen size.

After obtaining informed consent, all the patients included in the study were subjected to detailed history taking, clinical examination and relevant lab investigations including platelet count \& serum albumin concentration. Abdominal ultrasound was performed in all the patients with the measurement of right liver lobe diameter (in $\mathrm{cm}$ ) \& left liver lobe diameter (in $\mathrm{cm}$ ) in the mid-clavicular line \& central line, respectively. The bipolar spleen diameter (in $\mathrm{mm}$ ) was also measured on ultrasound. Upper GI endoscopy was performed in every patient for the detection \& grading of Oesophageal varices. Grading of Oesophageal varices was done as follows:(11),(15)

- Grade 0: No varices,

- Grade I: Small and straight varices at the level of mucosa,

- Grade II: Varices $<5 \mathrm{~mm}$, tortuous \& occupying less than one third of the Oesophageal lumen,

- Grade III: Varices $>5 \mathrm{~mm}$ \& occupying more than one third of the Oesophageal lumen,

- Grade IV: Varices occupying more than two third of the Oesophageal lumen.

RLLD/albumin ratio, LLLD/albumin ratio \& $\mathrm{PC} / \mathrm{SD}$ ratio were calculated for all the patients and their correlations with the presence \& grading of EV, were then comparatively evaluated \& statistically analysed.

The effect size was calculated using correlation between three ratios and grades of EV and average effect size was found out to be 0.824 , taking alpha error 0.05 and sample size 100 power achieved was $99.99 \%$, thus justifying our sample size of 100 .

Statistical analysis was performed by IBM-compatible Statistical Package for the Social Sciences (SPSS) version 20.0. The qualitative data were expressed as number (\%), while the continuous quantitative data as mean \pm standard deviation (SD) and the data was statistically analysed by 
using the following tests: Student t-test, Chi-square test, Wilcoxon Rank Sum test, Receiver operating characteristic (ROC) curve to detect area under curve (AUC), cut-off value for best sensitivity, specificity and accuracy. For evaluating the correlation between different parameters \& grading of $\mathrm{EV}, \mathrm{r}$ was calculated by Spearman's test for non-parametric correlation. A p-value of $<0.05$ was considered significant and at $<0.001$ was considered highly significant, while at $>0.05$ was considered not significant.

\section{RESULTS}

Out of total 100 patients, 82 were male \& rest 18 were female. Their age ranged from 19-75 years with the mean value of $47.29 \pm 11.57$ years. EVs were present in 82 patients and were absent in 18 patients. Patients without EV were taken as if with Grade 0 and patients with $\mathrm{EV}$ were further classified according to grading of EV into Grade I, II, III and IV. Grade I EVs were found in 18 patients, Grade II in 22 patients, Grade III in 22 patients and Grade IV in 20 patients. The main clinical characteristics of all patients are shown in table 1.

Platelet count was significantly decreased in patients with EV than those without EV $(\mathrm{p}<0.001)$ and spleen diameter was significantly increased in patients with EV than those without EV ( $p<0.001$ ) (Table 2). There was a statistically highly significant negative correlation between platelet count and grading of EV $(r=-0.688, p<0.001)$ and a statistically significant positive correlation between spleen diameter and grading of EV ( $\mathrm{r}=0.359, \mathrm{p}=0.001)$ (Table 3$)$.

$\mathrm{PC} / \mathrm{SD}$ ratio was significantly decreased in patients with $\mathrm{EV}$ than those without EV ( $\mathrm{p}<0.001$ ) (Table 2). PC/SD ratio was significantly decreased as the grade of EV increased in the patients. There was a statistically highly significant negative correlation between $\mathrm{PC} / \mathrm{SD}$ ratio and grading of EV $(r=-0.773, p<0.001)$ (Table 3 \& Figure 1).

RLLD/albumin ratio was significantly increased in RLLD/albumin ratio was significantly increased as the grade of EV increased in the patients. There was a statistically highly significant positive correlation between RLLD/albumin ratio and grading of EV $(r=0.522, p<0.001)$ (Table 3 \& Figure 2).

LLLD/albumin ratio was significantly increased in patients with EV than those without EV ( $p<0.001$ ) (Table 2). LLLD/albumin ratio was significantly increased as the grade of EV increased in the patients. There was a statistically highly significant positive correlation between LLLD/albumin $3)$.

The sensitivity, specificity, positive predictive value (PPV), negative predictive value (NPV) and accuracy of PC/SD ratio in prediction of $\mathrm{EV}$ was $90.2 \%, 88.9 \%, 97.4 \%, 66.7 \%$ patients with EV than those without EV ( $\mathrm{p}<0.001)$ (Table 2). ratio and grading of $\mathrm{EV}(\mathrm{r}=0.761, \mathrm{p}<0.001)$ (Table 3 \& Figure

and $90 \%$ respectively at the best cut-off value of 1167.25 as calculated by applying ROC curve (Figure 4) and area under curve (AUC) was 0.965 . The sensitivity, specificity, PPV, NPV and accuracy of RLLD/albumin ratio in prediction of EV was $74.4 \%, 94.4 \%, 98.4 \%, 44.7 \%$ and $78 \%$ respectively at the best cut-off value of 4.272 as calculated by applying ROC curve (Figure 5) and AUC was 0.835. The sensitivity, specificity, PPV, NPV and accuracy of LLLD/albumin ratio in prediction of $\mathrm{EV}$ was $89 \%, 83.3 \%, 96 \%, 62.5 \%$ and $88 \%$ respectively at the best cut-off value of 1.939 as calculated by applying ROC curve (Figure 6) and AUC was 0.931.

On comparing the three ratios, on the basis of sensitivity, specificity, accuracy \& AUC in prediction of EV (Table 4, Figures 7 \& 8) we found in our study that:

1. Sensitivity of PC/SD ratio > Sensitivity of LLLD/albumin ratio $>$ Sensitivity of RLLD/albumin ratio.

2. Specificity of RLLD/albumin ratio $>$ Specificity of PC/SD ratio $>$ Specificity of LLLD/albumin ratio.

3. Accuracy of PC/SD ratio > Accuracy of LLLD/albumin ratio $>$ Accuracy of RLLD/albumin ratio.

4. AUC of PC/SD ratio > AUC of LLLD/albumin ratio > AUC of RLLD/albumin ratio.

Therefore, PC/SD ratio, having the highest sensitivity, accuracy \& AUC, was the best predictor of EV, followed by the LLLD/albumin ratio, which was further followed by RLLD/albumin ratio.

\begin{tabular}{|c|c|}
\hline Total Number & $\mathbf{1 0 0}$ \\
\hline Sex (M/F) & $82 / 18$ \\
\hline Age (years; range) & $19-75$ \\
\hline Age (years; mean \pm SD) & $47.29 \pm 11.57$ \\
\hline $\begin{array}{c}\text { Oesophageal varices } \\
\text { (Present/absent) }\end{array}$ & $82 / 18$ \\
\hline $\begin{array}{c}\text { Grade of Oesophageal varices } \\
\text { (0/I/II/III/IV) }\end{array}$ & $18 / 18 / 22 / 22 / 20$ \\
\hline $\begin{array}{c}\text { Platelet count } \\
\text { (n/mm } \text {; mean } \pm \text { SD) }\end{array}$ & $129170.00 \pm 51742.18$ \\
\hline $\begin{array}{c}\text { Serum albumin } \\
\text { (g/dL; mean } \pm \text { SD) }\end{array}$ & $2.69 \pm 0.48$ \\
\hline $\begin{array}{c}\text { Right liver lobe diameter } \\
\text { (cm; mean } \pm \text { SD) }\end{array}$ & $12.64 \pm 2.81$ \\
\hline $\begin{array}{c}\text { Left liver lobe diameter } \\
\text { (cm; mean } \pm \text { SD) }\end{array}$ & $6.30 \pm 1.58$ \\
\hline $\begin{array}{c}\text { Spleen diameter } \\
\text { (mm; mean } \pm \text { SD) }\end{array}$ & $975.384 \pm 446.837$ \\
\hline $\begin{array}{c}\text { Platelet count/spleen diameter } \\
\text { ratio (mean } \pm \text { SD) }\end{array}$ & $4.79 \pm 1.20$ \\
\hline $\begin{array}{c}\text { Right liver lobe diameter/albumin } \\
\text { ratio (mean } \pm \text { SD) }\end{array}$ & $2.38 \pm 0.65$ \\
\hline $\begin{array}{c}\text { Left liver lobe diameter/albumin } \\
\text { ratio (mean } \pm \text { SD) }\end{array}$ & Table 1. Main Clinical Characteristics of All Patients \\
\hline Tain & \\
\hline
\end{tabular}

\begin{tabular}{|c|c|c|c|c|}
\hline & $\begin{array}{c}\text { EV Present } \\
(\mathbf{n = 8 2})\end{array}$ & $\begin{array}{c}\text { EV Absent } \\
(\mathbf{n = 1 8})\end{array}$ & $\begin{array}{c}\text { Total Patients } \\
(\mathbf{n = 1 0 0})\end{array}$ & p-value \\
\hline $\begin{array}{c}\text { Platelet count } \\
\left(\text { Mean } \pm \text { SD; } \mathrm{n} / \mathrm{mm}^{3}\right)\end{array}$ & $115329.27 \pm 35738.09$ & $192222.22 \pm 66121.60$ & $129170.00 \pm 51742.18$ & $<0.001$ \\
\hline Spleen diameter (Mean \pm SD; $\mathrm{mm})$ & $140.12 \pm 19.63$ & $121.08 \pm 22.65$ & $136.69 \pm 21.39$ & $<0.001$ \\
\hline PC/SD ratio (Mean \pm SD) & $834.873 \pm 267.266$ & $1615.491 \pm 541.594$ & $975.384 \pm 446.837$ & $<0.001$ \\
\hline RLLD/albumin ratio (Mean \pm SD) & $5.02 \pm 1.16$ & $3.74 \pm 0.67$ & $4.79 \pm 1.20$ & $<0.001$ \\
\hline LLLD/albumin ratio (Mean \pm SD) & $2.52 \pm 0.63$ & $1.76 \pm 0.32$ & $2.38 \pm 0.65$ & $<0.001$ \\
\hline \multicolumn{2}{|c|}{ Table 2. Different Parameters in Correlation to Presence or Absence of Oesophageal Varices } \\
\hline
\end{tabular}




\begin{tabular}{|c|c|c|c|c|c|c|c|c|}
\hline & $\begin{array}{c}\text { Grade } 0 \\
(n=18)\end{array}$ & $\begin{array}{l}\text { Grade I } \\
(n=18)\end{array}$ & $\begin{array}{c}\text { Grade II } \\
(n=22)\end{array}$ & $\begin{array}{c}\text { Grade III } \\
(n=22)\end{array}$ & $\begin{array}{c}\text { Grade IV } \\
(n=20)\end{array}$ & $\begin{array}{c}\text { Total } \\
\text { patients } \\
(\mathrm{n}=100)\end{array}$ & $\mathbf{r}$ & p-value \\
\hline $\begin{array}{c}\text { Platelet count } \\
\text { (Mean } \pm \mathrm{SD} ; \\
\mathrm{n} / \mathrm{mm}^{3} \text { ) }\end{array}$ & $\begin{array}{c}192222.22 \pm \\
66121.60\end{array}$ & $\begin{array}{c}140555.56 \pm \\
27032.06\end{array}$ & $\begin{array}{c}124272.73 \pm \\
29693.97\end{array}$ & $\begin{array}{c}110272.73 \pm \\
35044.44\end{array}$ & $\begin{array}{c}88350.00 \pm \\
31111.47\end{array}$ & $\begin{array}{c}129170.00 \pm \\
51742.18\end{array}$ & -0.688 & $<0.001$ \\
\hline $\begin{array}{c}\text { Spleen diameter } \\
(\text { Mean } \pm \text { SD; mm) }\end{array}$ & $\begin{array}{c}121.08 \pm \\
22.65\end{array}$ & $\begin{array}{c}134.28 \pm \\
22.09\end{array}$ & $\begin{array}{c}134.50 \pm \\
14.17\end{array}$ & $\begin{array}{c}145.27 \pm \\
17.84\end{array}$ & $\begin{array}{c}145.90 \pm \\
22.31\end{array}$ & $\begin{array}{c}136.69 \pm \\
21.39\end{array}$ & 0.359 & 0.001 \\
\hline $\begin{array}{c}\text { PC/SD ratio (Mean } \\
\pm \text { SD) }\end{array}$ & $\begin{array}{c}1615.491 \pm \\
541.594\end{array}$ & $\begin{array}{c}1053.645 \pm \\
176.986\end{array}$ & $\begin{array}{c}935.334 \pm \\
244.259\end{array}$ & $\begin{array}{c}763.581 \pm \\
231.812 \\
\end{array}$ & $\begin{array}{c}605.893 \pm \\
181.810 \\
\end{array}$ & $\begin{array}{c}975.384 \pm \\
446.837\end{array}$ & -0.773 & $<0.001$ \\
\hline $\begin{array}{c}\text { RLLD/albumin } \\
\text { ratio (Mean } \pm \text { SD) }\end{array}$ & $3.74 \pm 0.67$ & $4.59 \pm 0.73$ & $4.69 \pm 0.95$ & $4.79 \pm 0.85$ & $6.03 \pm 1.43$ & $4.79 \pm 1.20$ & 0.522 & $<0.001$ \\
\hline $\begin{array}{c}\text { LLLD/albumin } \\
\text { ratio (Mean } \pm \text { SD) }\end{array}$ & $1.76 \pm 0.32$ & $2.08 \pm 0.17$ & $2.19 \pm 0.30$ & $2.68 \pm 0.76$ & $3.09 \pm 0.49$ & $2.38 \pm 0.65$ & 0.761 & $<0.001$ \\
\hline \multicolumn{9}{|c|}{ Table 3. Different Parameters in Correlation to Grading of Oesophageal Varices } \\
\hline
\end{tabular}

\begin{tabular}{|c|c|c|c|c|c|c|c|}
\hline & Cut-off value & Sensitivity & Specificity & $\begin{array}{c}\text { Positive } \\
\text { Predictive } \\
\text { Value(PPV) }\end{array}$ & $\begin{array}{c}\text { Negative } \\
\text { Predictive } \\
\text { Value (NPV) }\end{array}$ & Accuracy & $\begin{array}{c}\text { Area Under } \\
\text { Curve } \\
\text { (AUC) }\end{array}$ \\
\hline PC/SD ratio & 1167.25 & $90.2 \%$ & $88.9 \%$ & $97.4 \%$ & $66.7 \%$ & $90 \%$ & 0.965 \\
\hline $\begin{array}{l}\text { RLLD/albumin } \\
\text { ratio }\end{array}$ & 4.272 & $74.4 \%$ & $94.4 \%$ & $98.4 \%$ & $44.7 \%$ & $78 \%$ & 0.835 \\
\hline $\begin{array}{l}\text { LLLD/albumin } \\
\text { ratio }\end{array}$ & 1.939 & $89 \%$ & $83.3 \%$ & $96 \%$ & $62.5 \%$ & $88 \%$ & 0.931 \\
\hline
\end{tabular}

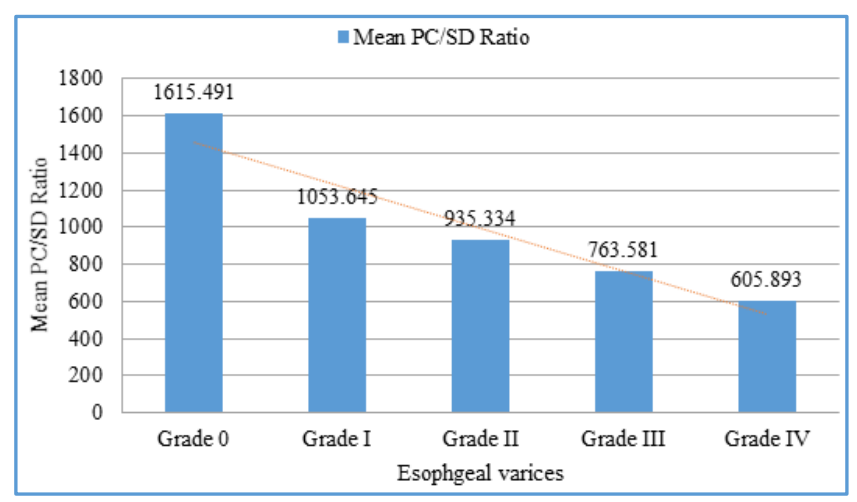

Figure 1. Platelet Count/Spleen Diameter (PC/SD) Ratio in Correlation with Oesophageal Varices

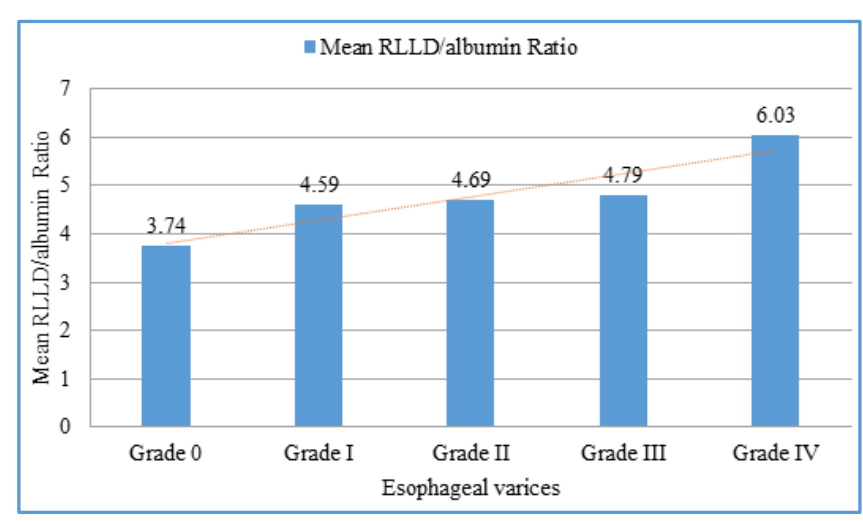

Figure 2. Right Liver Lobe Diameter (RLLD)/Albumin Ratio in Correlation with Oesophageal Varices

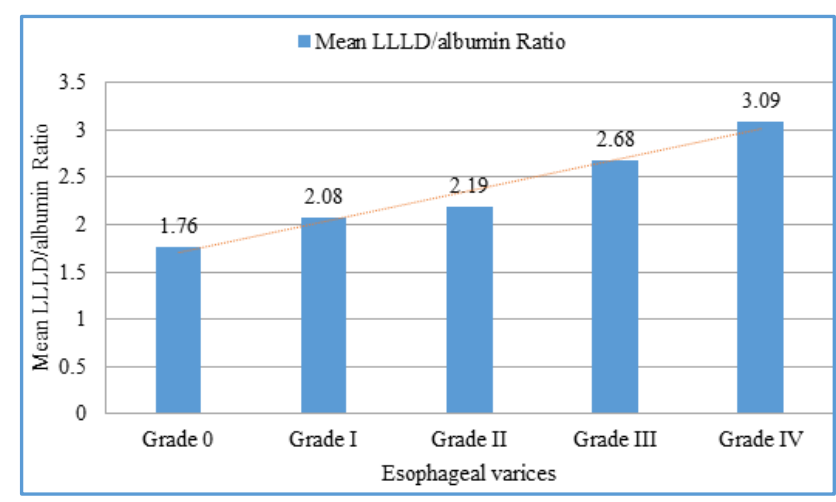

Figure 3. Left Liver Lobe Diameter (LLLD)/Albumin Ratio in Correlation with Oesophageal Varices

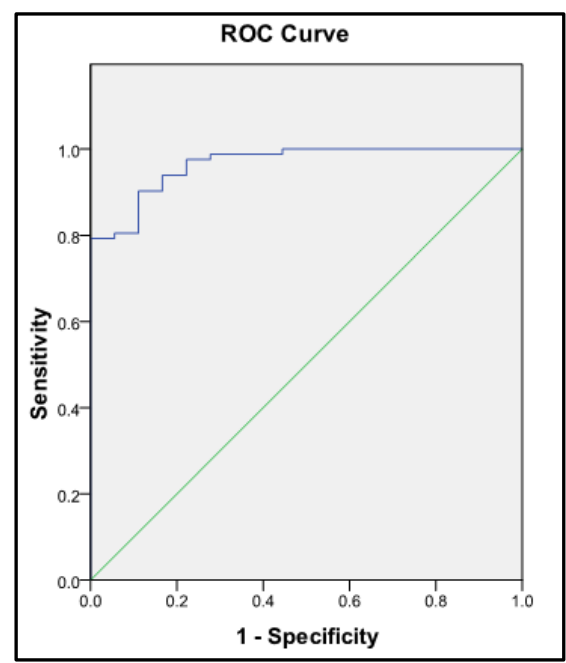

Figure 4. ROC (Receiver Operating Characteristic) Curve for Evaluation of PC/SD Ratio as Diagnostic Parameter for the Presence of Oesophageal Varices 


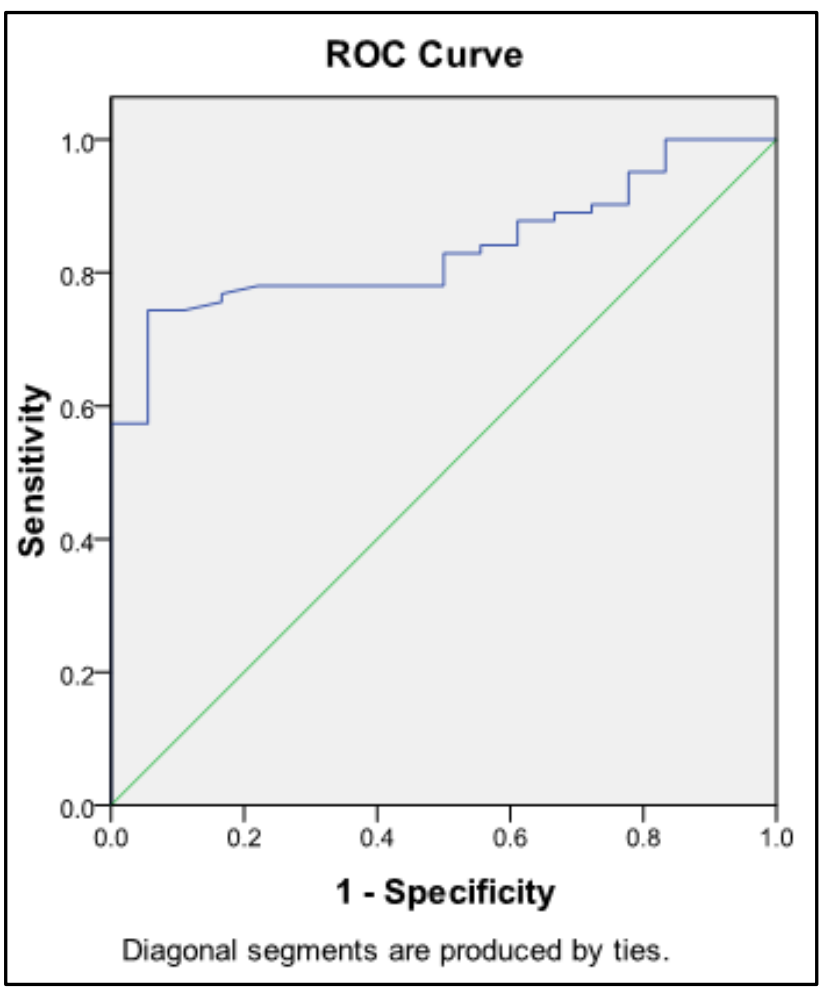

Figure 5. ROC (Receiver Operating Characteristic) Curve for Evaluation of RLLD/Albumin Ratio as Diagnostic Parameter for the Presence of Oesophageal Varices

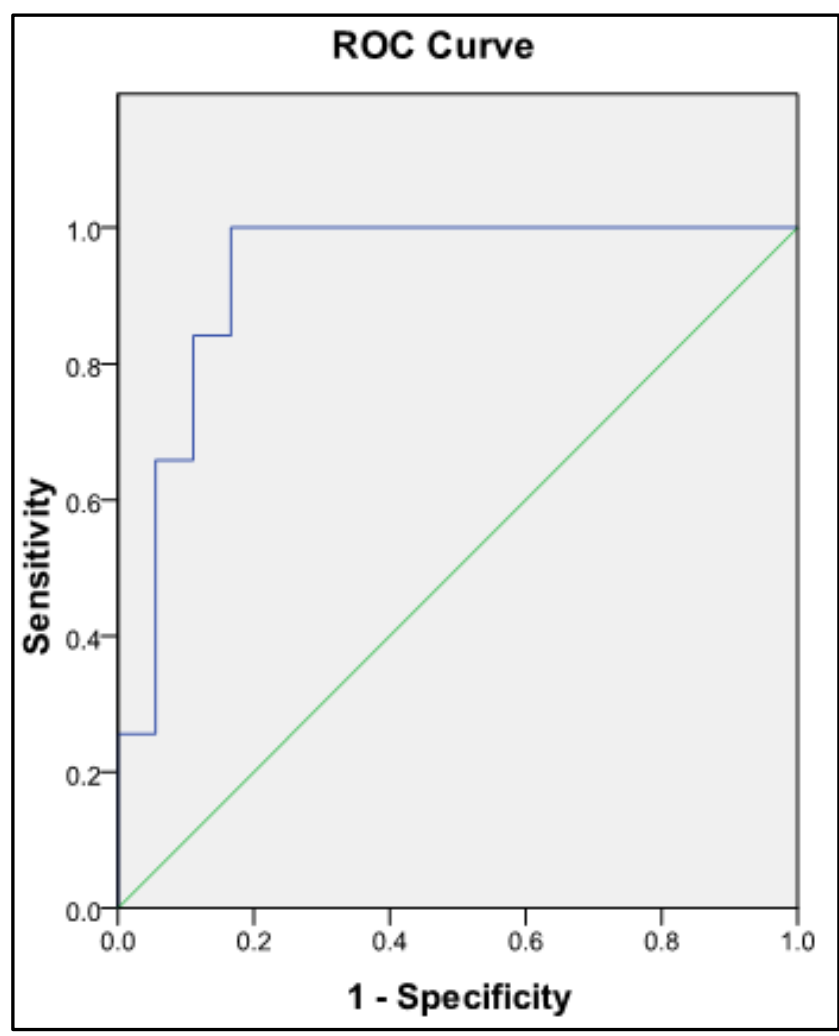

Figure 6. ROC (Receiver Operating Characteristic) Curve for Evaluation of LLLD/Albumin Ratio as Diagnostic Parameter for the Presence of Oesophageal Varices

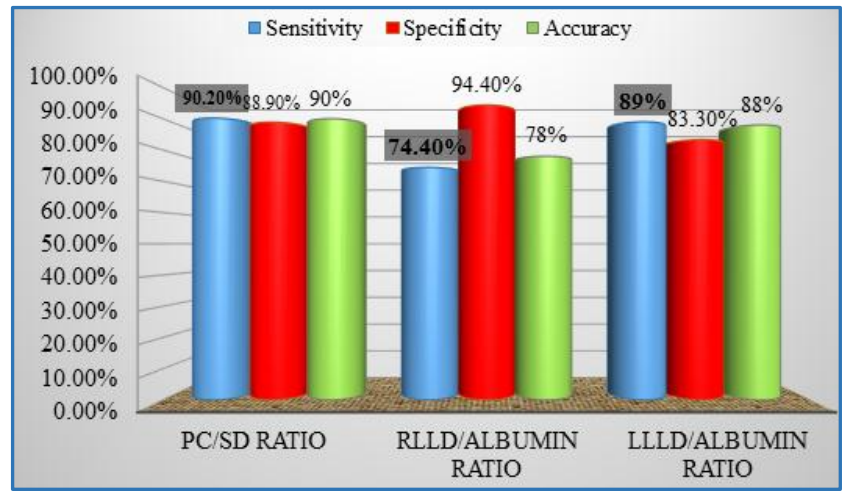

Figure 7. Comparison between Sensitivity, Specificity and Accuracy of PC/SD Ratio, RLLD/Albumin Ratio and LLLD/Albumin Ratio in Prediction of Oesophageal Varices

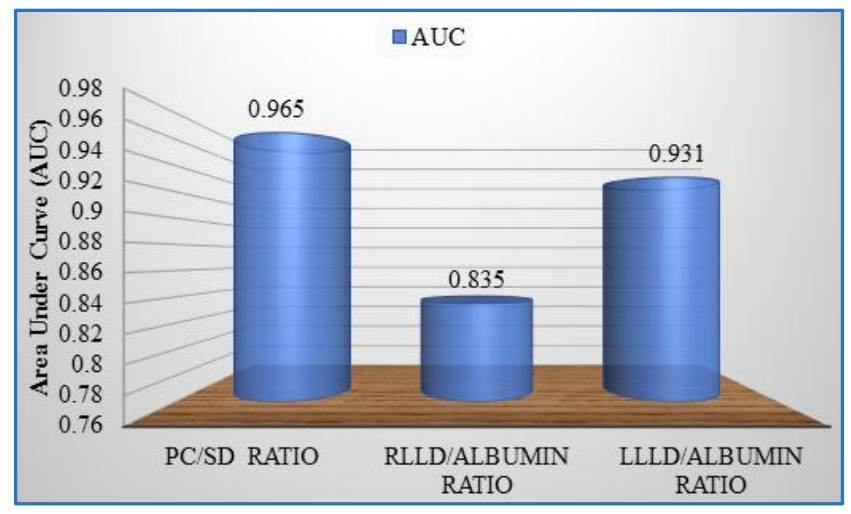

Figure 8. Comparison between Area Under Curve of PC/SD Ratio, RLLD/Albumin Ratio \& LLLD/Albumin Ratio in Prediction of Oesophageal Varices

\section{DISCUSSION}

Oesophageal varices (EV) development is among the major complications of liver cirrhosis, with an incidence of approximately $60-80 \%$.(1) Because of the impact of bleeding caused by rupture of $\mathrm{EV}$ in the prognosis of cirrhotic patients, the current guidelines recommend screening of all liver cirrhosis patients by repeated endoscopy.(7) However, repeated endoscopic examinations are unpleasant for the patients, are not cost-effective and pose additional burden to endoscopic units,(8),(16) especially in developing countries where the resources are limited, while only about half of cirrhotic patients have varices. Thus, the need for a simple, cheap and noninvasive method that can predict EV is of outmost importance to avoid endoscopy in patients with a low risk of varices. Therefore, various non-invasive parameters have been studied to predict EV in cirrhotic patients including platelet count/spleen diameter (PC/SD) ratio, right liver lobe diameter (RLLD)/albumin ratio and left liver lobe diameter (LLLD)/albumin ratio.

Aim of the present study was to comparatively evaluate $\mathrm{PC} / \mathrm{SD}$ ratio, RLLD/albumin ratio \& LLLD/albumin ratio as the non-invasive predictors of Oesophageal varices \& their grading in patients with liver cirrhosis. 
In our study, we found that platelet count was significantly decreased in patients with EV than those without EV $(\mathrm{p}<0.001)$ and in patients with $\mathrm{EV}$, there was a statistically highly significant negative correlation of platelet count with the grading of EV ( $\mathrm{r}=-0.688, \mathrm{p}<0.001)$. It was significantly decreased as the grade of EV increased. This finding goes similar with what has been reported in previous studies e.g. Zaman et al(17) reported that patients with platelet counts of less than $88000 / \mathrm{mm}^{3}$ have five times greater likelihood of having large Oesophageal or gastric varices as compared with the patients with higher platelet counts. Also low platelet count and splenomegaly were accurate to predict the presence of large EV as demonstrated by PeckRadosavljevic(18) and Sharma et al.(19) $\mathrm{Ng}^{(20)}$ also identified correlation between presence of thrombocytopenia and larger varices in the Chinese population. Similarly, Madhotra et $\mathrm{al}(21)$ in 2002, reported that platelet count less than $68000 / \mathrm{mm}^{3}$ have a larger discriminatory value. However, in cirrhotic patients, the presence of thrombocytopenia may be due to several factors other than portal hypertension including shortened mean platelet lifetime, decreased thrombopoietin production or the myelotoxic effects of hepatitis $\mathrm{C}$ virus.(10)

We also found in our study that spleen diameter was significantly increased in patients with EV than those without EV $(p<0.001) \&$ in the patients with EV, it was significantly increased as the grade of EV increased. There was a statistically significant positive correlation of spleen diameter with the grading of EV ( $\mathrm{r}=0.359, \mathrm{p}=0.001)$. This finding is similar to what has been stated by Amarapurkar et al(22) in 1994, who reported that splenomegaly alone was a significant predictor for the development of large EV. Similarly, Chalasani et al(18) in 1999, concluded that large EVs are predictable in thrombocytopenic patients who have enlarged spleen. In 2012, Esmat et al(23) found a highly statistically significant correlation of the presence and grade of EV with the splenic diameter $(p<0.001)$. The presence of splenomegaly in cirrhotic patients is mainly related to portal hypertension \& main mechanism of thrombocytopenia is splenic sequestration \& pooling.

In the present study, we found that there was a significant decrease in $\mathrm{PC} / \mathrm{SD}$ ratio in patients with $\mathrm{EV}$ than those without $\mathrm{EV}(\mathrm{p}<0.001)$ \& in patients with $\mathrm{EV}$, there was a statistically highly significant negative correlation between $\mathrm{PC} / \mathrm{SD}$ ratio and grading of EV $(\mathrm{r}=-0.773, \mathrm{p}<0.001)$. It was significantly decreased as the grade of EV increased. These results were similar to other studies which had suggested $\mathrm{PC} / \mathrm{SD}$ ratio as informative. e.g. Giannini et al(24), Alempijevic et al(12), Esmat et al(23), Mostafa et al(14) and several other studies had found a significant negative correlation of PC/SD ratio with presence \& size of EV. PC/SD ratio was introduced by Giannini et al(9) in 2003, so as to link thrombocytopenia to splenomegaly to introduce a variable that takes into consideration that thrombocytopenia is mainly due to hypersplenism secondary to portal hypertension.

In our study, the sensitivity of PC/SD ratio was $90.2 \%$, specificity was $88.9 \%$, PPV was $97.4 \%$, NPV was $66.7 \%$ and accuracy was $90 \%$, with the best cut-off value at 1167.25 , calculated by applying the ROC curve. AUC of PC/SD ratio in prediction of EV was 0.965 indicating its excellent predictability for EV. So we found PC/SD ratio useful in prediction of EV. In 2003, Giannini et al(9) concluded in their study that the PC/SD ratio is independently associated with the presence of Oesophageal varices. In 2006, Giannini et al(24) reported the results of a multicentre study that PC/SD ratio had $86.0 \%$ diagnostic accuracy for Oesophageal varices at cut-off value of 909 , which was significantly greater as compared with either accuracy of platelet count alone $(83.6 \%)$ or spleen diameter alone $(80.2 \%)$. This was confirmed by Agha et al(25) \& De Franchis R \& Dell'Era.(26) In 2008, Sen and Griffiths(27) also found that the PC/SD ratio was the most sensitive predictor for the presence of EV.

In 2008, Baig et al(28) also found in their study that the PC/SD ratio had higher accuracy for prediction of EV than the platelet count or spleen diameter alone. They reported that at the best cut-off value of $1014, \mathrm{PC} / \mathrm{SD}$ ratio gave the sensitivity of $98.1 \%$, specificity of $88.6 \%$, PPV of $95.4 \%$ and NPV of $95.1 \%$ in prediction of EV. The area under the ROC curve (AUC) was 0.942. The specificity, PPV and AUC for PC/SD ratio reported in this study are almost similar to those found in our study.

In 2011, Esmat and Rashid(29) found that the PC/SD ratio gave the highest accuracy (94\%) at a cut-off value of 1326.58 . Abu El Makarem MA et al(30) observed in their study that the PC/SD ratio in patients with EV was significantly lower than in patients without EV. They found an AUC of $0.94 \pm 0.02$, reflecting its overall diagnostic accuracy, almost similar to our study. In 2012, Chawla et al(31) reported the sensitivity of $89 \%$ and specificity of $74 \%$ at cut-off of 909 . Nisar et al(32) reported the PPV of $97.02 \%$ (same as ours) for PC/SD ratio \& concluded that it can be used for noninvasive diagnosis of EV. Ying et al(33) reported the sensitivity and specificity of the PC/SD ratio, at the threshold of 909 , as $92 \%$ and $87 \%$, respectively. In 2013, Mostafa $\mathrm{HM}$ et al(14) reported that sensitivity of PC/SD ratio was $96 \%$, specificity was $91 \%$ and the accuracy was $87.2 \%$ at a cut-off value of 528.6 (AUC=0.987). In 2015, Wadhwa et al(34) used the cut-off value of 1014 for PC/SD ratio \& found it a fairly accurate alternative in prediction of EV. Similarly, Gonzalez-Ojeda et al,(35) Tiwari et $\mathrm{al}^{(36)}$ \& Nayak et al(37) had concluded that $\mathrm{PC} / \mathrm{SD}$ ratio is a reliable tool for predicting EV.

In our study, we found that RLLD/albumin ratio was significantly increased in patients with EV than those without EV ( $p<0.001) \&$ in patients with EV, there was a statistically highly significant positive correlation between RLLD/albumin ratio and grading of EV $(r=0.522, p<0.001)$. It was significantly increased as the grade of EV increased. Similar significant positive correlation between RLLD/albumin ratio \& EV had been reported by Alempijevic et al(12), Said et al(38), Rye et al(39), Esmat et al(23), Mostafa et $\mathrm{al}^{(14)}$, Laeeq et $\mathrm{al}^{(13)} \&$ Sheta EAE et al.(40)

We found in our present study that at the best cut-off value of 4.272 for RLLD/albumin ratio, the sensitivity was $74.4 \%$, specificity was $94.4 \%$, PPV was $98.4 \%$, NPV was $44.7 \%$ and accuracy was $78 \%$ for the prediction of EV. AUC was 0.835 signifying its good predictability for EV. In comparison to our results, in 2007, Alempijevic T et al(11),(12) reported that at a cut-off value of 4.425 for RLLD/albumin ratio, the sensitivity was $83.1 \%$, and the specificity was $73.9 \%$ \& they concluded that RLLD/albumin ratio provided accurate information pertinent to determination of presence of EV and their grading. In a study by Mostafa HM et al(14) in 2013, RLLD/albumin ratio at a cut-off value of 4.7 significantly predicted presence of EV with 93\% sensitivity, 
95\% specificity and $96.5 \%$ accuracy (AUC $=0.953$ ). In a study by Sheta EAE et al(40) in 2016, RLLD/albumin at a cut-off value of $\geq 4.92$ significantly predicted presence of EV with $63.61 \%$ sensitivity, $97.67 \%$ specificity, PPV of $97.3 \%$ and a NPV of $66.7 \%$.

In the current study, we found that LLLD/albumin ratio was significantly increased in patients with EV than those without EV $(p<0.001)$ \& in patients with EV, there was a statistically highly significant positive correlation between LLLD/albumin ratio and the grading of EV ( $\mathrm{r}=0.574$, $\mathrm{p}<0.001$ ). It was significantly increased as the grade of EV increased in the patients. This finding goes similar to the study by Laeeq S Mudassir et al(13) who also found significant positive correlation between LLLD/albumin ratio \& EV $(\mathrm{p}<0.001)$.

We also found in our study that at the best cut-off value of 1.939 for LLLD/albumin ratio, the sensitivity was $89 \%$, specificity was $83.3 \%$, PPV was $96 \%$, NPV was $62.5 \%$ and accuracy was $88 \%$ for the prediction of EV. AUC was 0.931 signifying its excellent predictability for EV. Laeeq S Mudassir et al(13) found that at a cut-off value of 1.5 for LLLD/albumin ratio, the sensitivity was $88.1 \%$ and the specificity was $72.1 \%$ (AUC=0.69).

Therefore, with support from previous studies, we can conclude that all three ratios i.e. PC/SD ratio, RLLD/albumin ratio \& LLLD/albumin ratio have significant correlation with the presence \& grading of EV.

On comparing the three ratios, on the basis of sensitivity, specificity \& accuracy in prediction of $\mathrm{EV}$, we found in our study that-

1. Sensitivity of PC/SD ratio > Sensitivity of LLLD/albumin ratio > Sensitivity of RLLD/albumin ratio.

2. Specificity of RLLD/albumin ratio > Specificity of PC/SD ratio $>$ Specificity of LLLD/albumin ratio.

3. Accuracy of PC/SD ratio > Accuracy of LLLD/albumin ratio $>$ Accuracy of RLLD/albumin ratio.

Sen and Griffiths(27) suggested that noninvasive predictors of $\mathrm{EV}$ must have a high sensitivity, even at the cost of a lower specificity, to ensure that patients with varices are not missed. So, PC/SD ratio \& LLLD/albumin ratio, having higher sensitivity \& accuracy, are better predictors of EV than RLLD/albumin ratio, even at the cost of their lower specificity. PC/SD ratio, having even more sensitivity \& accuracy than LLLD/albumin ratio, is the best predictor. Mostafa HM et al(14) also found in their comparative study that the $\mathrm{PC} / \mathrm{SD}$ ratio had more sensitivity but lower specificity than RLLD/albumin ratio. Similar findings are reported in studies by Sheta EAE et al(40) \& Said HEE et al(38). Esmat $\mathrm{S}$ et al(23) found that PC/SD ratio had higher accuracy than RLLD/albumin ratio which is again in agreement with our study.

On comparing the three ratios, on the basis of Area under curve (AUC) of ROC curve for prediction of $\mathrm{EV}$, we found that: AUC of PC/SD ratio (0.965) > AUC of LLLD/albumin ratio (0.931) > AUC of RLLD/albumin ratio (0.835).

Higher the AUC, greater is the predictability for EV. So, in our study, PC/SD ratio, having highest AUC, was the best predictor of $\mathrm{EV}$, followed by the LLLD/albumin ratio, which was further followed by RLLD/albumin ratio. This is in agreement with the study by Laeeq S Mudassir et al(13) who concluded in their study that the LLLD/albumin ratio (AUC $=0.69$ ) is a better predictor of $\mathrm{EV}$ than the RLLD/albumin ratio (AUC=0.377). Mostafa HM et al(14) found that PC/SD ratio had higher AUC (0.987) than RLLD/albumin ratio (0.953) \& so better predictability. Currently, there is no study available in the literature for comparison of PC/SD ratio \& LLLD/albumin ratio.

Therefore, in summation of the study, we found that PC/SD ratio, having highest sensitivity, accuracy \& AUC, was the best predictor of EV, followed by the LLLD/albumin ratio, which was further followed by RLLD/albumin ratio.

\section{CONCLUSION}

$\mathrm{PC} / \mathrm{SD}$ ratio, RLLD/albumin ratio \& LLLD/albumin ratio are cost-effective noninvasive parameters that can provide accurate information pertinent to predict the presence and grading of EV in liver cirrhosis patients and amongst them $\mathrm{PC} / \mathrm{SD}$ ratio is the best predictor of $\mathrm{EV}$, followed by LLLD/albumin ratio, which is further followed by RLLD/albumin ratio. Despite a good correlation between these ratios and presence and grading of $\mathrm{EV}$, these cannot substitute for upper gastrointestinal endoscopy in the scrutiny of EV, but nevertheless, these can help physicians practising in rural areas where endoscopy facilities are not readily available and resources are limited, in helping them to initiate appropriate primary pharmacological prophylaxis in these patients. In an urban setting where the endoscopy workload is high, these noninvasive predictors can help one to initiate drug therapy while waiting for the endoscopy procedure or restricting the use of endoscopic screening only to patients presenting with a high probability of EV, and these can also serve for selection of patients who need more frequent endoscopies. However, further studies on larger groups of patients are needed for further validation of the results of the present study.

\section{REFERENCES}

[1] Jensen DM. Endoscopic screening for varices in cirrhosis: findings, implications, and outcomes. Gastroenterology 2002;122(6):1620-30.

[2] The North Italian Endoscopic Club for the Study and Treatment of Esophageal Varices. Prediction of the first variceal hemorrhage in patients with cirrhosis of the liver and esophageal varices. $\mathrm{N}$ Engl J Med 1988;319(15):983-9.

[3] Graham DY, Smith JL. The course of patients after variceal hemorrhage. Gastroenterology 1981;80(4):800-9.

[4] D'Amico G, Luca A. Natural history. Clinicalhaemodynamic correlations. Prediction of the risk of bleeding. Baillieres Clin Gastroenterol 1997;11(2):243-56.

[5] D'Amico G, Pagliaro L, Bosch J. Pharmacological treatment of portal hypertension: an evidence-based approach. Semin Liver Dis 1999;19(4):475-505.

[6] Imperiale TF, Chalasani N. A meta-analysis of endoscopic variceal ligation for primary prophylaxis of esophageal variceal bleeding. Hepatology 2001;33(4):802-7. 
[7] Garcia-Tsao G, Bosch J, Groszmann RJ. Portal hypertension and variceal bleeding--unresolved issues. Summary of an American association for the study of liver diseases and European association for the study of the liver single-topic conference. Hepatol Baltim Md 2008;47(5):1764-72.

[8] Merli M, Nicolini G, Angeloni S, et al. Incidence and natural history of small esophageal varices in cirrhotic patients. J Hepatol 2003;38(3):266-72.

[9] Giannini E, Botta F, Borro P, et al. Platelet count/spleen diameter ratio: proposal and validation of a non-invasive parameter to predict the presence of oesophageal varices in patients with liver cirrhosis. Gut 2003;52(8):1200-5.

[10] Peck-Radosavljevic M. Thrombocytopenia in liver disease. Can J Gastroenterol 2000;14(Suppl D):60D66D.

[11] Alempijevic T, Bulat V, Djuranovic S, et al. Right liver lobe/albumin ratio: contribution to non-invasive assessment of portal hypertension. World J Gastroenterol 2007;13(40):5331-5.

[12] Alempijevic T, Kovacevic N. Right liver lobe diameter: albumin ratio: a new non-invasive parameter for prediction of oesophageal varices in patients with liver cirrhosis (preliminary report). Gut 2007;56(8):1166-7.

[13] Mudassir LS, Hasan LN, Kumar WR, et al. Left liver lobe diameter albumin ratio as a predictor of esophageal varices in patients with cirrhosis: a preliminary report. J Transl Intern Med 2014;2(4):164-7.

[14] Mostafa HM, Eid KA, Meguid MMA, et al. Comparative study between right liver lobe diameter/albumin ratio and platelet count/spleen diameter ratio as a noninvasive predictor of oesophageal varices in patients with liver cirrhosis. ResearchGate 2013;81(1):875-85.

[15] Wehrmann T. Öseophagus diagnostisch und therapeutisch. In: Lembcke B, Wehrmann T, (eds). Die gastroenterologische endoskopie. Reinbeck: EinhornPresse Verlag 1999:56-83.

[16] De Franchis R. Noninvasive diagnosis of esophageal varices: is it feasible? Am J Gastroenterol 2006;101(11):2520-2.

[17] Zaman A, Hapke R, Flora K, et al. Factors predicting the presence of esophageal or gastric varices in patients with advanced liver disease. Am J Gastroenterol 1999;94(11):3292-6.

[18] Chalasani N, Imperiale TF, Ismail A, et al. Predictors of large esophageal varices in patients with cirrhosis. Am J Gastroenterol 1999;94(11):3285-91.

[19] Sharma SK, Aggarwal R. Prediction of large esophageal varices in patients with cirrhosis of the liver using clinical, laboratory and imaging parameters. J Gastroenterol Hepatol 2007;22(11):1909-15.

[20] Ng FH, Wong SY, Loo CK, et al. Prediction of oesophagogastric varices in patients with liver cirrhosis. J Gastroenterol Hepatol 1999;14(8):785-90.

[21] Madhotra R, Mulcahy HE, Willner I, et al. Prediction of esophageal varices in patients with cirrhosis. J Clin Gastroenterol 2002;34(1):81-5.
[22] Amarapurkar DN, Parikh SS, Shankaran K, et al. Correlation between splenomegaly and oesophageal varices in patients with liver cirrhosis. Endoscopy 1994;26(6):563.

[23] Esmat S, Omarn D, Rashid L. Can we consider the right hepatic lobe size/albumin ratio a noninvasive predictor of oesophageal varices in hepatitis $C$ virusrelated liver cirrhotic Egyptian patients? Eur J Intern Med 2012;23(3):267-72.

[24] Giannini EG, Zaman A, Kreil A, et al. Platelet count/spleen diameter ratio for the noninvasive diagnosis of esophageal varices: results of a multicenter, prospective, validation study. Am J Gastroenterol 2006;101(11):2511-9.

[25] Agha A, Anwar E, Bashir K, et al. External validation of the platelet count/spleen diameter ratio for the diagnosis of esophageal varices in hepatitis $\mathrm{C}$ virusrelated cirrhosis. Dig Dis Sci 2009;54(3):654-60.

[26] de Franchis R, Dell'Era A. Diagnosis and therapy of esophageal vascular disorders. Curr Opin Gastroenterol 2007;23(4):422-7.

[27] Sen S, Griffiths WJH. Non-invasive prediction of oesophageal varices in cirrhosis. World J Gastroenterol 2008;14(15):2454-5.

[28] Baig WW, Nagaraja MV, Varma M, et al. Platelet count to spleen diameter ratio for the diagnosis of esophageal varices: is it feasible? Can J Gastroenterol 2008;22(10):825-8.

[29] Esmat S, Rashid L. A comparative study between three noninvasive predictors of oesophageal varices in post hepatitis C virus liver cirrhosis in Egypt. Acta GastroEnterol Belg 2011;74(4):497-502.

[30] El Makarem AMA, Shatat ME, Shaker Y, et al. Platelet count/bipolar spleen diameter ratio for the prediction of esophageal varices: the special Egyptian situation: noninvasive prediction of esophageal varices. Hepatitis monthly 2011;11(4):278-84.

[31] Chawla S, Katz A, Attar BM, et al. Platelet count/spleen diameter ratio to predict the presence of esophageal varices in patients with cirrhosis: a systematic review. Eur J Gastroenterol Hepatol 2012;24(4):431-6.

[32] Nisar S, Nazir S, Butt A, et al. Validity of platelet count/spleen diameter ratio for the noninvasive diagnosis of esophageal varices in cirrhotic patients. ResearchGate 2012;6(1):269-74.

[33] Ying L, Lin X, Xie ZL, et al. Performance of platelet count/spleen diameter ratio for diagnosis of esophageal varices in cirrhosis: a meta-analysis. Dig Dis Sci 2012;57(6):1672-81.

[34] Wadhwa RK, Abbas Z, Mujahid HS, et al. Platelet count to splenic diameter ratio and splenoportal index as non-invasive screening tools in predicting esophageal varices in patients with liver cirrhosis. J Transl Intern Med 2014;2(3):127-31.

[35] González-Ojeda A, Cervantes-Guevara G, ChávezSánchez $\mathrm{M}$, et al. Platelet count/spleen diameter ratio to predict esophageal varices in Mexican patients with hepatic cirrhosis. World J Gastroenterol 2014;20(8):2079-84. 
[36] Tiwari D, Kumar S, Lahariya D, et al. Comparison between platelet count, spleen diameter and their ratio with esophageal varices in patients with liver cirrhosis. Am J Med Med Sci 2016;6(1):29-33.

[37] Nayak OP, Sukhwani N. A study of platelet count/ spleen diameter ratio as a predictor of esophageal varices in patients of cirrhosis. Int J Med Res Rev 2016;4(4).

[38] Said HEE, Elsayed EY, Ameen A, et al. Cytopenia as a predictor of oesophageal varices in patients with liver cirrhosis. Report and Opinion 2010;2(7):35-41.
[39] Rye K, Scott R, Mortimore G, et al. Towards noninvasive detection of oesophageal varices. Int J Hepatol 2012;2012:9.

[40] Sheta EAE, Yousef M, Abd-Elsalam S, et al. Noninvasive diagnosis of esophageal varices: can it replace screening endoscopy? Int J Curr Microbiol App Sci 2016;5(5):701-15. 